\title{
Global Impact of Digital Transformation on Entrepreneurship: Present Position in Spain
}

\begin{abstract}
By Juan José Morillas Guerrero*
The application of new information and communication technologies (ICTs) is a daily element in our current reality. However, these technologies are producing impacts of great importance in society and companies. It is widely agreed that we are facing a process of digital transformation that moves the productive sectors and social groups towards what we might call a global technological order. But how this situation affects one of the levers of that same digital transformation, the entrepreneurial ecosystem? And how has all this been impacted by globalization? Spain, at present, seems to be in a privileged position in terms of the main dimensions of digital competitiveness, at least within the $E U$, and, mainly, concerning digital public services. However, entrepreneurship reality in our country does not quite take off despite the high rate of youth unemployment we suffer. We still do not have a high-standard entrepreneurial activity that mainly tends towards innovation and disruptive changes. We neither manage to arouse interest in the massive creation of high-tech startups that could create a complementary framework to medium and large companies. There were many steps towards a deep digital transformation in our country. Nevertheless, it remains to be seen if this circumstance transcends the mere quantitative indicators and manages to reach the situation of entrepreneurial ecosystem. This article aims to discover the relationships between digital transformation, the world of entrepreneurship and the creation of companies related to Spain, nowadays, in order to establish the possible effects that both perspectives would accumulate reciprocally and also to clear up if we are facing singularities that would identify the processes being produced, such as "startuprization", enabling companies to grow with the subsequent global economic development.
\end{abstract}

Keywords: digital transformation, entrepreneurship, globalization, startups, entrepreneurial ecosystem

\section{Introduction}

Nowadays, the new information and communication technologies (ICTs) are having an enormous overall influence at all levels: political, business, cultural or social. All processes are being affected by a global interconnection that is producing paradigmatic changes, coming to involve a whole digital transformation.

This transformative movement has also reached entrepreneurship that has traditionally been a driving force of the innovation and the business and economic

\footnotetext{
*Assistant Professor, Higher Technical School of Aeronautical and Space Engineering (ETSIAE), Universidad Politécnica de Madrid, Spain. ORCID 0000-0002-9949-2070.
} 
growth. The new ideas of companies are being based on the disruptive advances that have allowed these ICTs.

However, the relationship between the two phenomena has not been studied: on the one hand, the transformative digital technologies of business and economic reality and, on the other, the entrepreneurial initiative within a peculiar ecosystem such as the creation of companies.

If we begin the analysis with the Spanish case, at first sight we find a situation that we could qualify, at least, as paradoxical. This is because the main dimensions that try to quantify the digital competitiveness of our country affirm a quite positive situation and, mostly, in relation to digital public services (see the basic results of the 2019 Country Report for Spain DESI, Digital Economy and Society Index, prepared by the European Commission and which is part of this work's analysis).

On the other hand, Spain does not have a high business activity that would allow the development of new companies (see the results on the entrepreneurial ecosystem of the GEM Report for Spain 2018-2019, prepared by Global Entrepreneurship Monitor and that will be the other great data source for this article), while we are going through a period of high youth unemployment along with some economic slowdown.

Therefore, we find an interesting issue that arouses research interest in the specific case of Spain as a country with high digitalization conditions, but with few entrepreneurial stimuli. Hence it becomes the need of discovering and analysing the situation to give a scientific explanation to this fact: Why the data in our country lead us to a profound digital transformation, while not accompanying the situation of entrepreneurship?

This paper has a clear purpose: establishing whether there are relationships between digital transformation, the world of entrepreneurship and business creation, and determining if these possible relationships explain the specific Spanish case and its economic behaviour.

In addition, it would venture out possible circumstances or processes that maybe occur in our territory. Among these phenomena, it will have special detail in the "startuprization": Spontaneous creation or birth of small but highly disruptive companies that could be the new nature of entrepreneurship in the digital revolutionary paradigm. These companies are subject to high disruptive innovations that would improve the business structure and could accelerate a consequent or deeper economic development compared with past times.

The present work consists of a review of the scientific doctrine expressed regarding the matter. An exposition and justification of the methodology used to present the research hypotheses with the variables examined from the two major international reports on the subject: DESI and GEM. Then, it continues with a detailed presentation of the results obtained with the corresponding explanatory graphs of these investigative findings. And finally, it ends with a discussion about these results and possible conclusions in this regard. 


\section{Literature Review}

The research that relates digital innovation or the situation of digital transformation with entrepreneurship does not have much follow-up in scientific doctrine. So, we can say that we are facing a new field in terms of analysis and publication. However, it is not a negative situation; by contrast it is an opportunity to open new research lines of great interest for the part of academic world dedicated to digital issues and business creation.

In addition, we could say that we are facing a path of search for answers requested by the natural evolution of companies' digitalization, and of today's society in general. In this respect, we find one of the main references in the publications of some prestigious researchers (Nambisan et al. 2019), especially North Americans and British. These authors manifest, after the 2000s, that the first allusions would focus on taking advantage of the benefits that the digital could have for entrepreneurship (Hull et al. 2007).

As of this date, doctrinal contributions have endeavored to understand the implications that digital technologies, some disruptive, were producing in the company and its structures (Autio et al. 2018), also in other aspects of business, such as customer experiences, for example (De la Boutetière et al. 2018). We have to refer to recent research to understand what has happened in almost a decade of the emergence of technologies and the impact they have had on business models or the genesis of entrepreneurial ecosystems (Autio et al. 2018).

The turning point came from those who related entrepreneurship and the three classic factors: opportunities, risk taking and tenacity to implement business creation initiatives, but this was done in isolation without considering the interactions that could be established among them (Hitt et al. 2011). Subsequently, they continued with the relationship between innovation and opportunities from technologies (Nambisan 2017).

All this leads us to affirm that, until now, it was studied - and the doctrine is unanimous, in this matter - that innovative advances from ICTs produce a stimulus for trade, and this leads to economic growth by increasing consumer surplus. In addition to the traditional theory of value creation, it was key in economic development (Schumpeter 1934), attending one of the clearest relations between innovation and entrepreneurship.

On the one hand, we find the generation of benefits as a result of the digital transformation, through the so-called digital dividends (Galindo-Martín et al. 2019). But until the most recent publications in this regard, there had been no such a deep overlap between digital and entrepreneurship, even though the term "digital entrepreneurship" (DE) had already been taken into account in the scientific literature much earlier (Matlay and Westhead 2007, Walker 2006, Yen et al. 2002).

However, on the other hand, the clear relationship between innovation and digital transformation was discussed (Amit and Zott 2001, Gavron 1998) that would take us from digital to economic growth through entrepreneurship and its implications. And the welfare loop has even been unravelled precisely because of the interaction between a better digital situation and its translation to the creation 
of innovative companies, and therefore to entrepreneurship in general (ZorteaJohnston et al. 2012) given the implementation of technologies in the private sphere as well as in public administrations (Giones and Brem 2017).

All this would take us to a new time in the investigation of business and its ecosystems when the two coincide: the digital and the entrepreneur (Sahut et al. 2019).

This is where this paper is inserted, trying to provide with empirical data, a perspective on Spain's current situation in terms of digital entrepreneurship, correlating the most recent parameters on the economy and digital society in this country against the point at which the entrepreneurial phenomenon is found quantitatively and qualitatively. We seek to unravel the hypotheses in this regard and clear up the unknowns about whether, today, our country creates the technological bases that will encourage entrepreneurship, and this, in turn, encouraging the appropriate economic and development growth.

\section{Methodology}

The 2019 Index of the Digital Economy and Society was consulted, and specifically, the Country Report for Spain (DESI, European Commission 2019) that determines the analysis of situation for the economy and digital society in each of the EU member countries through the corresponding country profiles grouped into five specific thematic chapters. These index dimensions are: 1 . Connectivity; 2. Human capital; 3. Use of internet services; 4. Integration of digital technology; and 5. Digital public services. In addition, various aspects were incorporated into the report in order to keep in mind the latest technological advances, underlying data and new trends (e.g., digitalization of companies, 5G, women and ICTs, online voting, electronic medical prescriptions, etc.).

However, this report has never been proven in relation to digital transformation, the world of entrepreneurship and the creation of high-tech companies. To avoid this bias and abound in possible correlations - as the main objective of this paper the GEM Spain 2018-2019 Report, Global Entrepreneurship Monitor (CISE 2019) will be consulted, which leads to a stable and rigorous methodology in monitoring the entrepreneurial ecosystem in Spain.

It is organized in the entrepreneurial phenomenon analysis in our country, valuing population, business, innovation, and internationalization variables; also, in the study of the entrepreneurial environment, through the conditions for the exercise of entrepreneurial activity in Spain by Autonomous Communities and cities.

With these two sources of information and data, the corresponding statistical treatment was carried out to discover the correlations that could be extracted for the purpose of possible connected variables that ratify or not the work hypotheses.

First, the fundamental indicator of the entrepreneurial process and its aspirations in terms of activity were put in relation to verify possible interactions. In order to do so, the following entrepreneurial parameters were chosen, as described in Table 1, from the point of view of the entrepreneurial ecosystem, 
starting with TEA $^{1}$ (variable No. 1) as a pivot on which measuring entrepreneurial activity.

Table 1. GEM Variable Selection

\begin{tabular}{|l|l|}
\hline Variable type & \multicolumn{1}{c|}{ Description } \\
\hline 1. & Total entrepreneurial activity rate (TEA), by age and by gender. \\
\hline 2. & Values and attitudes for entrepreneurship. \\
\hline 3. & Degree of novelty (innovation) of products and services. \\
\hline
\end{tabular}

Source: CISE 2019.

With the two remaining variables (No. 2 and 3) a qualitative analysis was carried out to determine the influence between these and the general digital situation described for Spain.

For the digital ecosystem of economic and social development, the following eleven most outstanding digital parameters were chosen, according to the analytical blocks into which the report is divided as described in Table 2.

Table 2. DESI Variable Selection

\begin{tabular}{|l|l|}
\hline Variable type & \\
\hline 1. & Connectivity \\
\hline $1 \mathrm{~b} 1$. & 4 Gescription \\
\hline $1 \mathrm{c} 1$. & New generation broadband coverage (NGA) \\
\hline $1 \mathrm{~d} 2$. & Implementation of ultrafast broadband \\
\hline 2. & Human capital \\
\hline $2 \mathrm{~b} 1$. & ICT specialists \\
\hline $2 \mathrm{~b} 2$. & Women ICT specialists \\
\hline 3. & Use of internet services \\
\hline $3 \mathrm{c} 1$. & Banking (users) \\
\hline $3 \mathrm{c} 3$. & Online sale (users) \\
\hline 4. & Digital technology integration \\
\hline $4 \mathrm{a} 1$. & Electronic exchange of information (companies) \\
\hline $4 \mathrm{a} 2$. & Social networks (companies) \\
\hline $4 \mathrm{~b} 2$. & E-commerce turnover (SMEs) \\
\hline 5. & Digital public services \\
\hline $5 \mathrm{a} 1$. & Users of the electronic administration \\
\hline
\end{tabular}

Source: Own elaboration based on DESI variables and descriptions.

Thus, we have a complete mapping of the relationships between variables for each of the main blocks (see Table 3). From the analysis of Connectivity, the 4G coverage in Spain was studied in terms of the percentage of households that have this technology through the average of operators. New generation broadband coverage (NGA) by the percentage in households, as well as the implementation of ultra-fast broadband was also considered.

\footnotetext{
${ }^{1}$ TEA (Total Entrepreneurial Activity) or rate of entrepreneurs with early-stage companies (nascent and new) is calculated as the percentage of the adult population (between 18 and 64 years) in each country/region/city, owners or co-owners of newly created companies that have persisted in the market for a period between 0 and 42 months (3.5 years).
} 
Table 3. Correlations between DESI Variables and the Situation of Entrepreneurship in Spain

\begin{tabular}{|l|}
\hline Variables GEM/DESI \\
\hline TEA/Connectivity \\
\hline 1 vs. $1 \mathrm{~b} 1$ \\
\hline 1 vs. $1 \mathrm{c} 1$ \\
\hline 1 vs. $1 \mathrm{~d} 2$ \\
\hline TEA/Human capital \\
\hline 1 vs. $2 \mathrm{~b} 1$ \\
\hline 1 vs. $2 \mathrm{~b} 2$ \\
\hline TEA/Use of internet services \\
\hline 1 vs. $3 \mathrm{c} 1$ \\
\hline 1 vs. $3 \mathrm{c} 3$ \\
\hline TEA/Digital technology integration \\
\hline 1 vs. $4 \mathrm{a} 1$ \\
\hline 1 vs. $4 \mathrm{a} 2$ \\
\hline 1 vs. $4 \mathrm{~b} 2$ \\
\hline TEA/Digital public services \\
\hline 1 vs. $5 \mathrm{a} 1$ \\
\hline
\end{tabular}

Source: Own elaboration based on GEM and DESI variables.

As regards Human capital, the use of ICT specialists was taken with respect to the total percentage of employment, as well as the ratio of ICT specialists' women within the percentage of female employment.

Two of the most interesting values were taken for the analysis of the Use of internet services: Internet banking services through the percentage of users of these services on the Internet, together with online sales also measured by the percentage of Internet users for this type of digital commerce.

Bellow, for the Integration of digital technology analysis, which is one of the most interesting situation's blocks for our work, electronic exchanges of information between companies were taken through their corresponding percentage. The use of social networks by companies expressed as a percentage was also measured and, as a third variable, the turnover of e-commerce was used with its percentage value.

Finally, it was treated the important block of Digital public services that gives a very interesting idea of the Spanish situation in its digital advance, standing in the fourth place among the EU countries. Here it was used the percentage of internet users who need to submit forms to the Administration. Nowadays, it is a fact that $76 \%$ of Spanish internet users actively participating in electronic administration services.

\section{Results}

In general terms, following the data available as a result of the DESI, it is observed that Spain's position in terms of the main dimensions of the report is 
above the European average and, in general, it is a situation that we could define as a privilege facing the main digital challenges.

As can be seen in Figure 1, all dimensions are above the average (EU-28), except for human capital; especially highlighting the results in the fifth dimension referring to digital public services that double the standardized values for Europe.

Figure 1. Results of Relative Performance by Dimension of the Index of the Digital Economy and Society in Spain and Europe

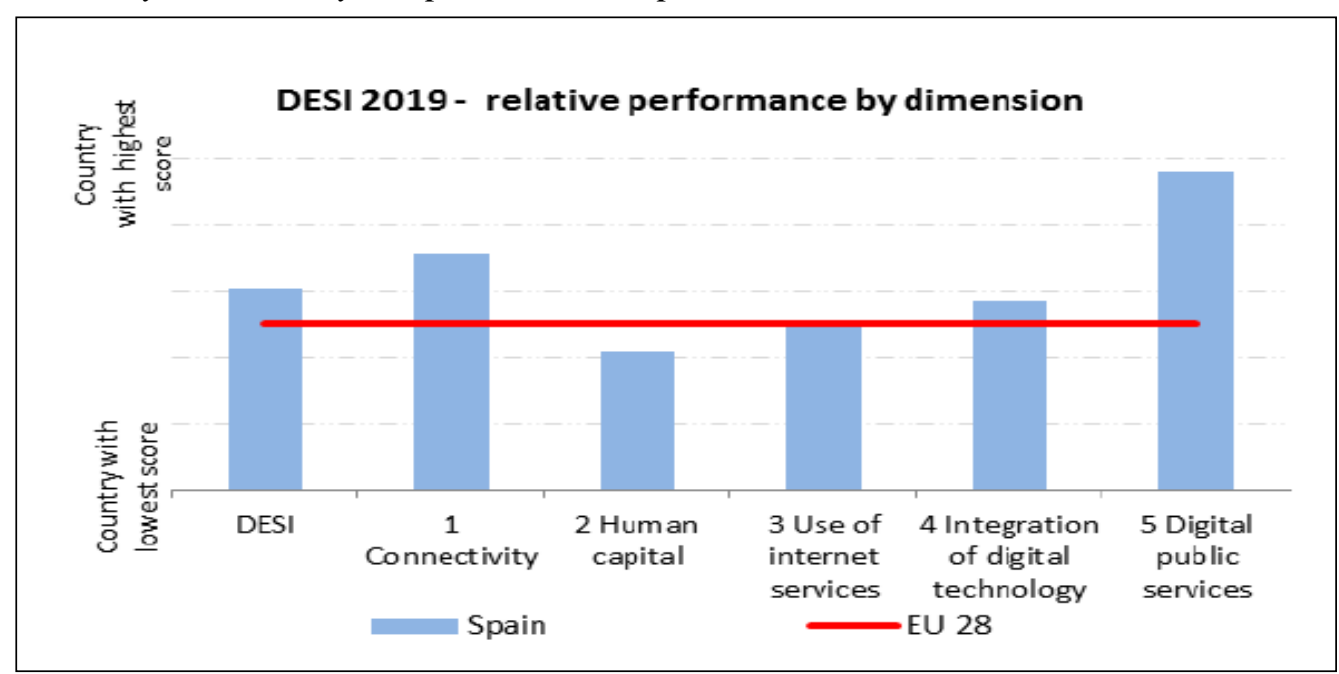

Source: DESI, European Commission 2019.

Although this situation is encouraging, however, when we cross the data with the entrepreneurial intention - as is the object of this paper - we appreciate that the clear advantage of Spain is significantly depreciated in the panorama of European countries (see Figure 2).

We observe in the right margin of this graph the list of European countries ordered from highest to lowest according to their index of economy and digital society while comparing with their entrepreneurship rate (TEA) for 2019; proving that the $11^{\text {th }}$ position of Spain in digitalization does not correspond to the tendency of the large entrepreneurial countries, where Estonia stands out with the highest degree of European entrepreneurship (19.38\%), and also the most advanced group in this aspect such as the Netherlands, Malta, Lithuania, Slovakia, Austria and Luxembourg do it.

While the best placed in digitalization are the Scandinavian countries, only four countries share positions in both ratios (Netherlands, Luxembourg, Estonia, and Malta), above the Spanish position on the DESI ranking $\left(>11^{\text {th }}\right)$. 
Figure 2. Relationship between the TEA Entrepreneurship Indicator and the Digital Economy and Society Index in the EU Zone

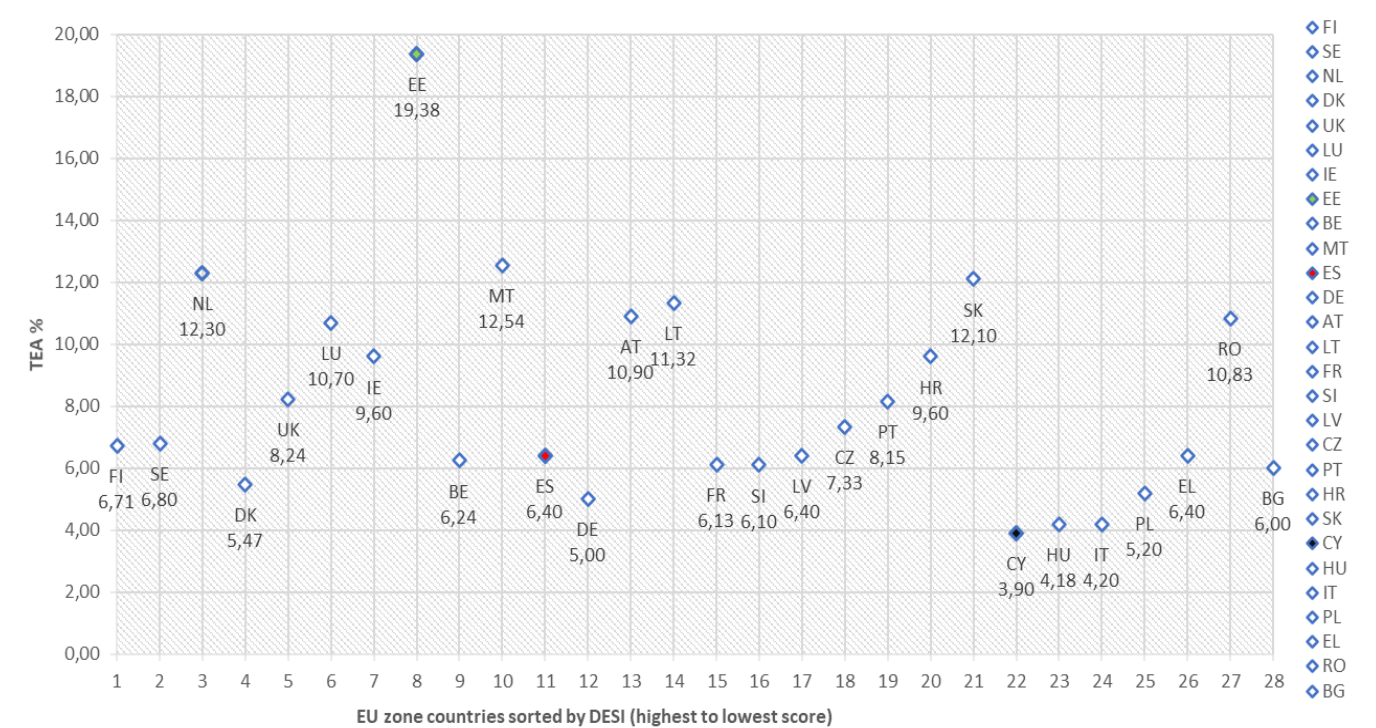

Source: Own elaboration based on Bosma et al. (2018) and DESI, European Commission (2019).

In our study we have discovered a curious fact, namely that both Spain and Germany are well placed in digitalization - and play economically main roles within the EU - but their entrepreneurship rates are relatively low (6.4\% and 5\%, respectively) which makes us reflect on the discrepancy between these two fields.

In its turn, the country with the worst TEA, Cyprus, also shares worse positions in digitalization and entrepreneurship, together with Hungary, Italy, and Poland. Special mention is required to the case of Romania with the placed second to last in digital society and, nevertheless, with one of the best entrepreneurship rates scoring $10.83 \%$.

Another of the areas studied was the employment situation in new information technologies (ICTs), where the situation in Spain was the most inflationary. This can be easily seen in Figure 3 where the rates of employees specialized in ICTs, men, and women, were compared over the total number of employees in general, and it can be seen that Spain has a very low representation of women specialists, which turns out to be the biggest deficit in the "Human Capital" section of the digitalization situation for our country. 
Figure 3. ICT Employment Situation in Relation to the Total in Spain

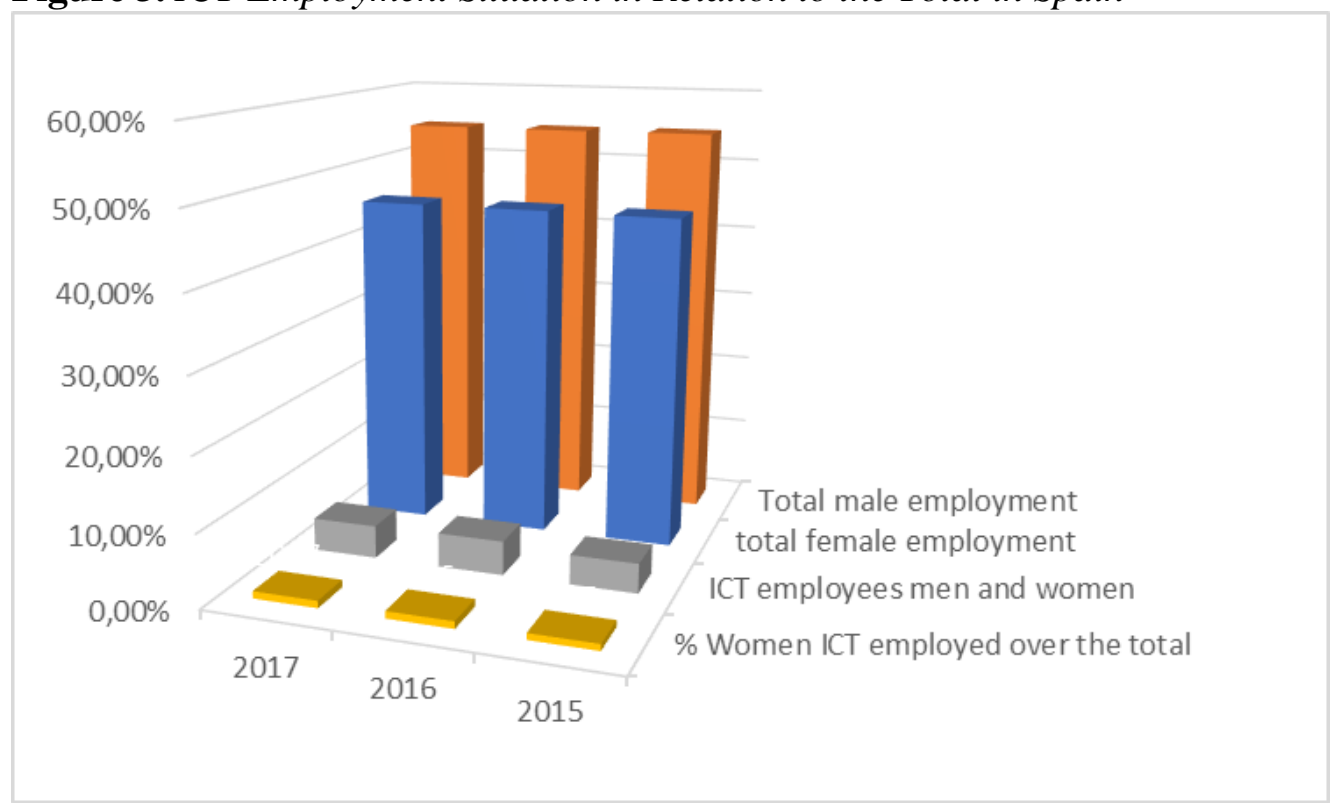

Source: Own elaboration based on DESI, European Commission (2019) and INE (2019).

It is clear that this deficiency is very relevant for the economic and digital society improvement in relation to the rest of Europe and world situation. There is a great lack of ICT specialists regarding the active population $(2.9 \%$ vs. $3.7 \%)$ in the EU. But the most significant thing is that women who specialize in ICTs do not reach $1 \%$ of total female employment in Spain.

Moreover, if we cross the European Commission data with the ones from the Spanish Statistics National Institute (INE) we obtain interesting results. To begin with, the total number of men employed in the Spanish labour market for 2017 was $54.54 \%$ while the percentage of women was $45.46 \%$, almost ten points less. In addition, in the field of ICTs, the rates are low for both genders and very low for women employed in ICTs, taking the total share of female employment $(0.45 \%)$.

In addition, the rate practically remains unchanged throughout the time series (2015-2017) where we can compare for the case of the digital society index. This means that we are facing a very delicate challenge since on one side there is a high digital potential for our country, but that can go unnoticed while this "gender gap" exists in ICT jobs.

In this analysis, the digitalization data comparison and its current level with the entrepreneurial situation was relevant. It can be seen in Figure 4 how the entrepreneurial rate in men and women has substantial differences $(6.80 \%$ and $5.60 \%$ for the year 2017, respectively) despite the representation of women employed in ICTs is so low. This leads us to think that entrepreneurial initiatives in our country are far from ICTs, regardless of the correlations we have obtained in this study and will be discussed later. 
Figure 4. Relationship between the TEA Entrepreneurship Indicator and ICT Employment Situation in Spain

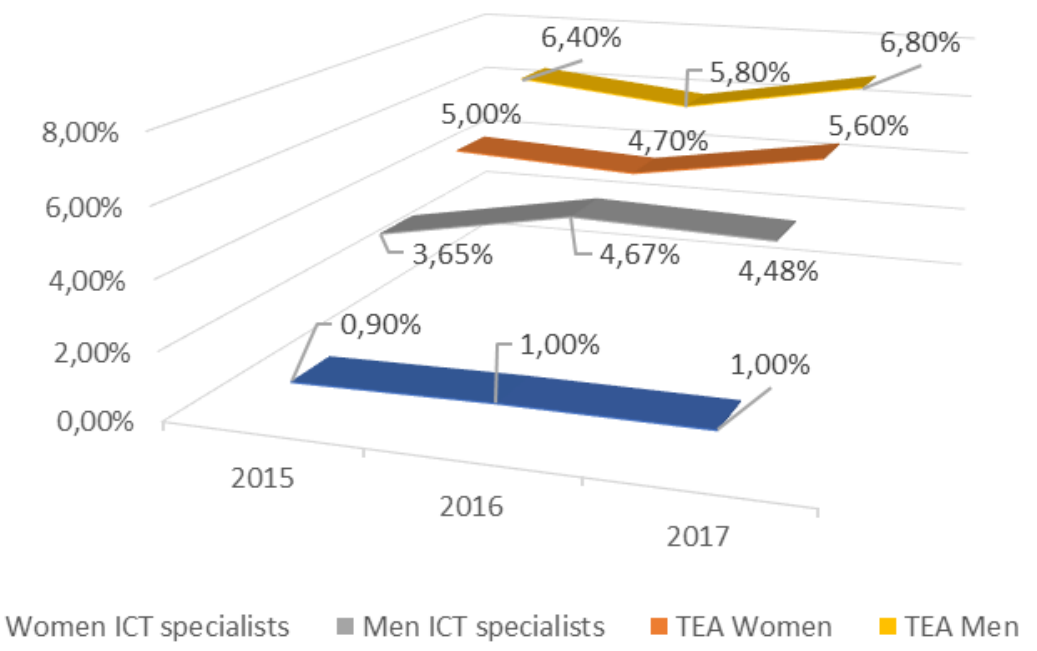

Source: Own elaboration based on DESI, European Commission (2019), CISE (2019) and INE (2019).

Going deeper into this aspect of entrepreneurship and gender, regarding the situation in our country according to the GEM data (CISE 2019), we have analyzed the values and attitudes of the Spanish population between 18 and 64 years involved in the entrepreneurial process, according to a series of Personal perceptions and then, comparing them with the entrepreneurship rate (TEA), we have reached the following results.

The first of the perceptions that was asked in the report was "... there are opportunities to undertake in the next 6 months" where the greater optimism of men over women was appreciated. In the second, it was asked about "... have the knowledge and skills to undertake", verifying that both men and women were quite sure of their knowledge, although the difference of opinion was only a little over two points. However, when the question was directed to the perception of "... fear of failure as an obstacle to entrepreneurship", here men did not reveal their insecurities unlike women (rates were almost three points less). Finally, in the perception of whether "... meet other people who have undertaken the previous year", the relationship was favourable to men in more than 5 points (see all this in Figure 5). 
Figure 5. Values and Attitudes of Entrepreneurship: Relationship between the \% of the Spanish Population of 18-64 Years by Sex Involved in the Entrepreneurial Process "that perceives..." and the Entrepreneurship Indicator (TEA) by Sex in Spain.

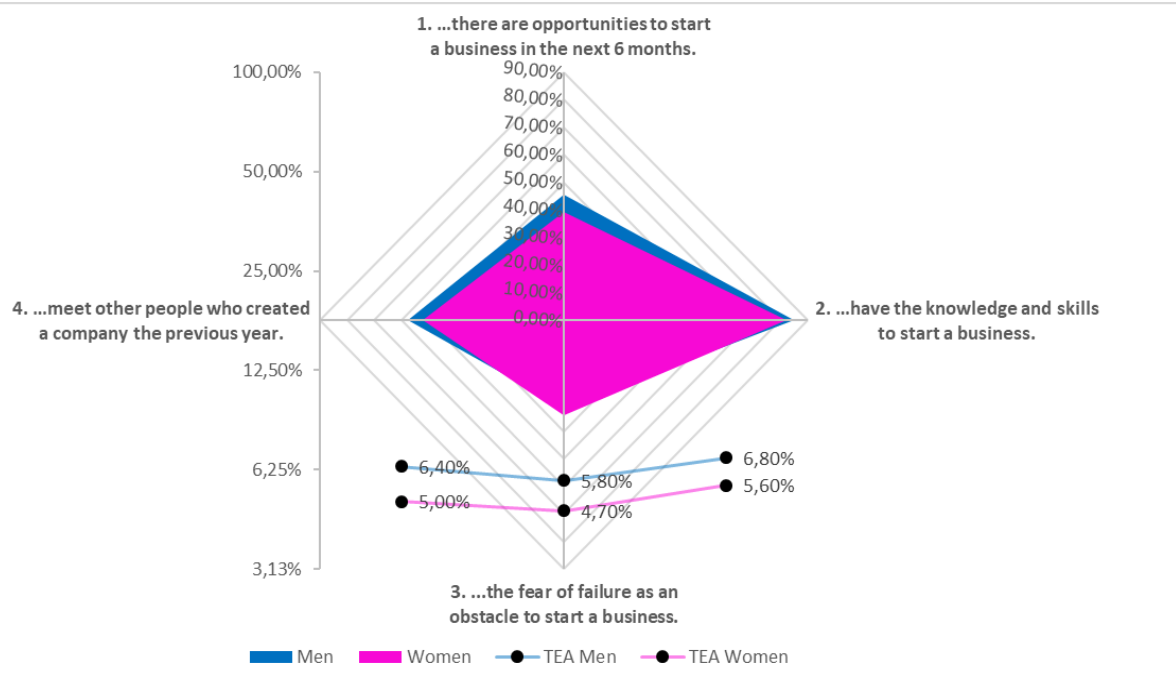

Source: Own elaboration based on DESI, European Commission (2019) and CISE (2019).

Following the methodology of our study, and before focusing on the correlations, we have analysed the relationship between connectivity indicators and the degree of novelty or innovation of products and services launched by the entrepreneurs.

With this we close the qualitative analysis considering the situation of technological advancement in connectivity on our country according to the economic and digital society index and if this is considering the innovative orientation. It could be thought about the technological development of new forms of connectivity, such as new generation broadband (NGA), ultra-fast broadband and $4 \mathrm{G}$ itself, and if entrepreneurs take advantage of these changes and digital transformations to find new products and services.

The three scales of innovation for products and services can be observed (see Figure 6): completely, something and nothing innovative. Although there are high percentages of entrepreneurs who confess not to be influenced by innovative technology, however, the rate has increased for cases where products and services were launched with some innovation, matching with the improvement of $4 \mathrm{G}$ and NGA connectivity, although very little for ultra-fast broadband. 
Figure 6. Relationship between the Connectivity Ratio and the Degree of Novelty of Products and Services between Entrepreneurs in the Initial Phase (TEA) in Spain in the Last Three Years

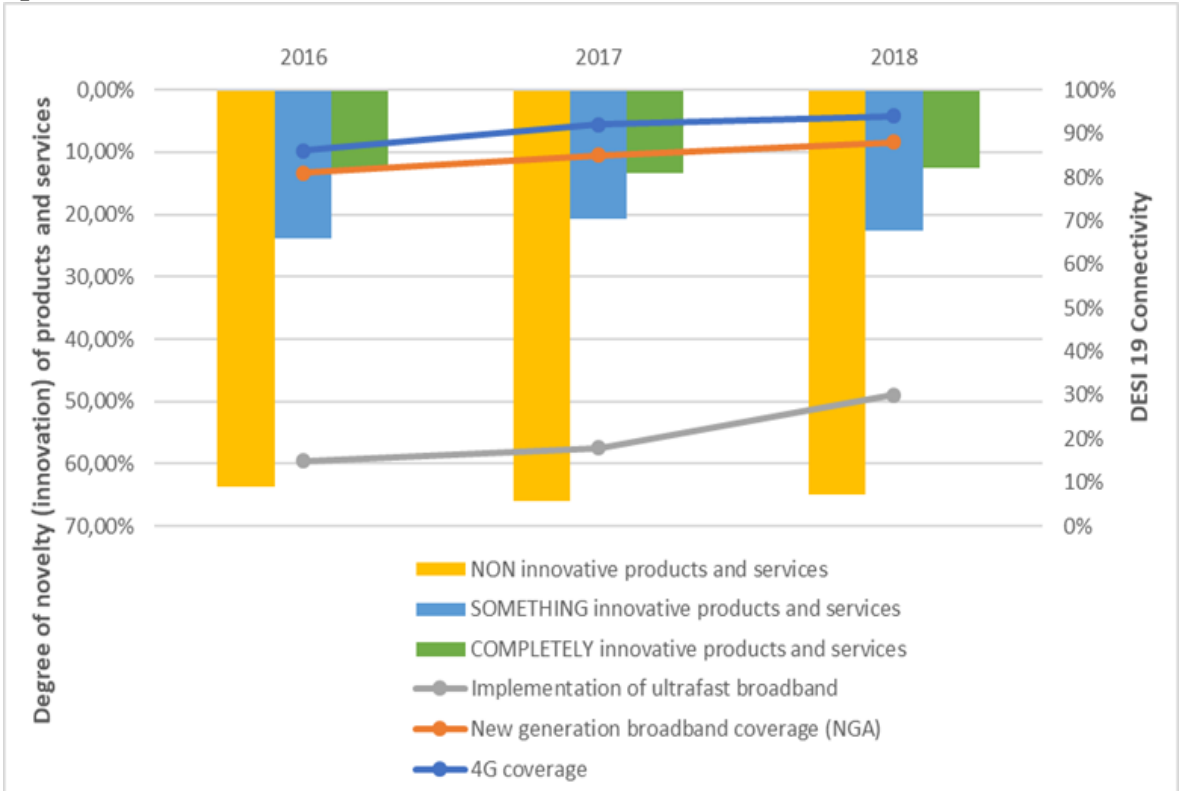

Source: Own elaboration based on DESI, European Commission (2019) and Bosma et al. (2018).

To finish with the results, we will define those obtained in terms of the correlations between variables that were part of this article's methodology. Table 4 shows the correlations that had been raised based on the corresponding working hypothesis of whether there was or not a positive relationship that confirmed them, or on the other side, the hypotheses obtained could be ruled out.

Table 4. Correlations between DESI Variables and the Situation of Entrepreneurship in Spain

\begin{tabular}{|c|c|c|c|}
\hline $\begin{array}{l}\text { Variables } \\
\text { GEM/DESI }\end{array}$ & $\begin{array}{c}\text { Pearson's linear } \\
\text { correlation } \\
\text { coefficient }\end{array}$ & $\mathbf{R}^{\wedge} \mathbf{2}$ & $\Sigma$ errors $^{\wedge} 2$ \\
\hline \multicolumn{4}{|c|}{ TEA/Connectivity } \\
\hline 1 vs. $1 \mathrm{~b} 1$ & 0.996 & 0.996 & 0.277 \\
\hline 1 vs. $1 \mathrm{c} 1$ & 0.990 & 0.995 & 0.340 \\
\hline 1 vs. $1 \mathrm{~d} 2$ & 0.764 & 0.923 & 5.743 \\
\hline \multicolumn{4}{|c|}{ TEA/Human capital } \\
\hline 1 vs. $2 b 1$ & -1.156 & 0.977 & 0.372 \\
\hline 1 vs. $2 \mathrm{~b} 2$ & 0.000 & 0.989 & 0.731 \\
\hline \multicolumn{4}{|c|}{ TEA/Use of internet services } \\
\hline 1 vs. $3 \mathrm{c} 1$ & 0.849 & 0.993 & 44.988 \\
\hline 1 vs. $3 \mathrm{c} 3$ & -0.629 & 0.973 & 11.885 \\
\hline \multicolumn{4}{|c|}{ TEA/Digital technology integration } \\
\hline 1 vs. $4 \mathrm{a} 1$ & 0.000 & 0.972 & 108.045 \\
\hline 1 vs. $4 \mathrm{a} 2$ & 0.988 & 0.999 & 0.990 \\
\hline 1 vs. $4 \mathrm{~b} 2$ & 0.988 & 0.999 & 0.990 \\
\hline \multicolumn{4}{|c|}{ TEA/Digital public services } \\
\hline 1 vs. $5 \mathrm{a} 1$ & 0.697 & 58.480 & 0.994 \\
\hline
\end{tabular}

Source: Own elaboration based on GEM and DESI variables and data analytic. 
Well, from the calculations made we deduce that there is a correlation and, therefore, all the hypotheses for the "Connectivity" block in relation to the venture are confirmed. What implies that technological advances in connectivity, or its improvement, facilitating that individuals, homes and, above all, companies have more connectivity to networks, influences the promotion of greater entrepreneurship.

However, quite the opposite is true for the "Human Capital" block. There is no correlation between the two variables studied. In this way, we cannot affirm that the situation of the gender gap in spatialized ICT jobs imply that the entrepreneurship rate is affected. Thus, despite the dark panorama due to the lack of ICT specialists, and even more, of female representation, entrepreneurship in Spain remains at average values, although it is true that it also falls slightly in the case of women entrepreneurs.

When we have dealt with the hypothesis of the "Use of internet services" block, we can deduct from the data that, depending on what type of services we are assessing, there is a correlation or not. Thus, in the case of banking services, their development affects the entrepreneurship rate, and supposedly, the improvement of these will influence that. While in the case of online sales, the hypothesis has not been fulfilled, as Internet users (quite another thing will be the turnover of SMEs, e-commerce, which is included in the next block).

Next, within the "Integration of digital technology" block, there were confirmations on the variables of social networks and turnover of electronic commerce, for SMEs. Which would mean that a better situation of integration of digital technologies by companies - where Spain occupies a $10^{\text {th }}$ position regarding all EU countries - has a correlation in entrepreneurship, while the simple fact of electronic exchange of information, measured in percentage of companies that carry it out (variable 4a1), does not affect a higher entrepreneurship rate.

Lastly, focusing on the "Public Services" block, it is found that here the situation in Spain is very favourable, occupying the $4^{\text {th }}$ position among all EU countries. However, when we launch the possible relationship with the Spanish entrepreneurship rate, this hypothesis is ruled out. Whereby we can affirm that the existence of good electronic administration services, measured according to the percentage of internet users who need to submit forms, does not influence in the progress made on users who decides the creation of companies.

\section{Conclusions}

This work has used two of the most important reports that were made for Spain in terms of its index of economy and digital society and the one referring to the situation of entrepreneurship, both on its most updated versions, providing a methodology of complete results that has been able to give a quantitative and qualitative vision of great interest.

From the data obtained, the initial hypothesis is confirmed in the way that, although Spain occupies a certain privileged position in terms of its digital competitiveness, at least within the EU, and, above all, in relation to digital public 
services, this does not mean that there is an exact translation in the entrepreneurial system, and its main indicators.

Thus, Spain has a high-level connectivity infrastructure that will undoubtedly help stimulate business creation, although these potentialities are not fully exploited, for example, in the case of ultra-fast broadband. It may happen that entrepreneurship in Spain is more linked to more traditional sectors and not as disruptive as the inertia of the global situation could mean.

Another main conclusion is that, although we have a significant gender gap in specialized ICT jobs, however, this handicap will not affect entrepreneurial initiatives, maintaining entrepreneurship rates not so different in both men and women. And despite the high youth unemployment rate ${ }^{2}$ Spain supports, the digital transformation does not push this sector of the population towards the creation of companies.

Finally, there is a predisposition of digital improvement in terms of the use of social networks and internet business (e-commerce) that causes a relationship with entrepreneurship, while the fact of electronic information exchange by companies does not produce an increasing in business creation. This could be conditioned by bureaucratization in the company's creation process where perhaps there is a lot more still to be done ${ }^{3}$ even in this country. New lines of research on digitalization and reasons for entrepreneurship or the role of disruptive innovation are now opened.

\section{Acknowledgments}

I would like to thank, first, the authors of the DESI and GEM reports, the European Commission and the Santander Entrepreneurship and Global Entrepreneurship Research Association (GERA) International Centre, for their contributions to the study and investigation of the situation in Europe and Spain in digital society and entrepreneurship, respectively. It is a work of high value for researchers who can verify data and make measurements that would otherwise be impossible. I would also like to thank ATINER and my University, the Universidad Politécnica de Madrid (https://www.upm.es/) and my School, the Higher Technical School of Aeronautical and Space Engineering (https://www.etsiae.upm.es/) for the reception of my work and research as well as for the support that was always given to me to attend congresses and to make my research results public.

\footnotetext{
${ }^{2}$ Spain has a national youth unemployment rate of $31.68 \%$ for both sexes, under 25 years, according to the data for the 3Q of 2019. (INE 2019)

${ }^{3}$ According to the most recent data, Doing Business database, the situation of Spain in the process for the creation of companies has led him to the 30th position with a score of 77.9 within the 190 main economies of the world (International Bank for Reconstruction and Development 2019).
} 


\section{References}

Amit R, Zott C (2001) Value creation in e-business. Strategic Management Journal 22(67): 493-520.

Autio E, Nambisan S, Thomas LDW, Wright M (2018) Digital affordances, spatial affordances, and the genesis of entrepreneurial ecosystems. Strategic Entrepreneurship Journal 12(1): 72-95.

Bosma N, Kelley D, Global Entrepreneurship Research Association - GERA (2018) Global entrepreneurship monitor 2018/2019 global report. Chile.

Centro Internacional Santander Emprendimiento - CISE (2019) GEM, global entrepreneurship monitor. Informe España 2019. Santander.

De la Boutetière H, Montagner A, Reich A (2018) Unlocking success in digital transformations. In McKinsey \& Company.

DESI, Comisión Europea (2019) Índice de la Economía y la Sociedad Digitales (DESI) Informe de país 2019 España. (Digital Economy and Society Index (DESI) country report 2019 Spain). UE.

Galindo-Martín MÁ, Castaño-Martínez MS, Méndez-Picazo MT (2019) Digital transformation, digital dividends, and entrepreneurship: a quantitative analysis. Journal of Business Research 101(Aug): 522-527.

Gavron R (1998) The entrepreneurial society. Institute for Public Policy Research.

Giones F, Brem A (2017) Digital technology entrepreneurship: a definition and research agenda. Technology Innovation Management Review 7(5): 44-51.

Hitt MA, Ireland RD, Sirmon DG, C. A. T. (2011) Strategic entrepreneurship: creating value for individuals, organizations, and society. Academy of Management Perspectives 25(2): 127-135.

Hull CE, Hung YTC, Hair N, Perotti V, Demartino R (2007) Taking advantage of digital opportunities: A typology of digital entrepreneurship. International Journal of Networking and Virtual Organisations 4(3): 290-303.

Instituto Nacional de Estadística - INE (2019) Encuesta de Población Activa - EPA. (Labor force survey). Spain: INE.

International Bank for Reconstruction and Development (2019) Doing business 2020. comparing business regulation in 190 economies. The World Bank.

Matlay H, Westhead P (2007) Innovation and collaboration in virtual teams of eentrepreneurs: case evidence from the European tourism industry. The International Journal of Entrepreneurship and Innovation 8(1): 29-36.

Nambisan S (2017) Digital entrepreneurship: toward a digital technology perspective of entrepreneurship. Entrepreneurship: Theory and Practice 41(6): 1029-1055.

Nambisan S, Wright M, Feldman M (2019) The digital transformation of innovation and entrepreneurship: progress, challenges, and key themes. Research Policy 48(8): 1-9.

Sahut J-M, Iandoli L, Teulon F (2019) The age of digital entrepreneurship. Small Business Economics (Sep).

Schumpeter J (1934) Teoría del desarrollo económico. (Theory of economic development). Inglaterra: Universidad de Harvard.

Walker H (2006) The virtual organisation: a new organisational form? International Journal of Networking and Virtual Organisations 3(1): 25-41.

Yen D, Chou DC, Chen T, Chen H-G (2002) Becoming a virtual organisation: a strategic approach. International Journal of Networking and Virtual Organisations 1(2): 184198. 
Vol. 7, No. 2 Morillas-Guerrero: Global Impact of Digital Transformation on...

Zortea-Johnston E, Darroch J, Matear S (2012) Business orientations and innovation in small and medium sized enterprises. International Entrepreneurship and Management Journal 8(2): 145-164. 